\title{
LUXAÇÃO UNILATERAL CONGÊNITA DA PATELA EM FELINO: RELATO DE CASO
}

\begin{abstract}
MENDES, Patrícia Franciscone ${ }^{1}$ BRASIL, Fabrício Bernardo de Jesus $^{2}$

RESUMO: A luxação patelar caracteriza-se pelo deslocamento medial ou lateral, intermitente ou permanente da patela, pode ocorrer devido à hipoplasia do sulco troclear, deslocamento do quadríceps ou da crista tibial. Esta afecção pode ser de origem congênita, traumática, evolutiva ou sedentária, apresentando maior prevalência em cães de raças de pequeno porte sendo raramente diagnosticada em gatos. A sintomatologia é variável conforme o grau de luxação. O tratamento conservativo contempla repouso, administração de analgésicos e fisioterapia, o tratamento cirúrgico é mais comumente realizado, visto que na maioria das vezes os sinais clínicos manifestados pelos animais são mais evidentes somente em uma fase tardia da doença.
\end{abstract}

Palavras-chave: Luxação. Patela. Gatos.

SUMMARY: The patellar luxation is characterized by the medial or lateral dislocation, intermittent or permanent of patella, it occur due to hypoplasia of the trochlear grooves, quadriceps or tibial crest displacement. It can have a congenital, traumatic, evolutive or sedentary origin, which more prevalent in small dogs breeds and rarely in cats. The symptomatology varies with the degree of luxation. The conservative treatment consists in repose, analgesic administration and fisiotherapy, the surgical treatment is more common because the majority of the clinical signs manifested by the animals are evident just in a late phase of the disease.

Key-words: Luxation. Patella. Cats.

\section{INTRODUÇÃO}

A luxação patelar caracteriza-se pelo deslocamento medial ou lateral, intermitente ou permanente da patela, pode ocorrer devido ao arrasamento do sulco troclear, deslocamento do quadríceps ou da crista tibial (HULSE; JOHNSON, 2003).

É considerada uma das afecções mais comuns que ocorre envolvendo a articulação fêmuro-tíbio-patelar, pode ser de origem congênita, traumática, evolutiva ou sedentária, apresentando maior prevalência em cães de raças de pequeno porte sendo incomum em gatos (HULSE; JOHNSON, 2003).

A hipoplasia do músculo vasto medial pode ser considerada o fator iniciante da luxação patelar lateral de origem congênita. Este músculo é o último a se desenvolver no

\footnotetext{
${ }^{1}$ Acadêmica do Curso de Medicina Veterinária do Centro Regional Universitário de Espírito Santo do Pinhal SP (UNIPINHAL).

${ }^{2}$ Professor Dr. das disciplinas de Técnica Cirúrgica e Métodos e Diagnóstico por Imagem do Curso de Medicina Veterinária do Centro Regional Universitário de Espírito Santo do Pinhal - SP (UNIPINHAL).
} 
grupo do quadríceps e fixa-se à patela juntamente com o músculo vasto lateral, auxiliando na estabilidade patelar, impedindo o deslocamento lateral da patela, ao contrabalançar a tração exercida pelo vasto lateral e vasto intermédio, durante a extensão do joelho (BOJRAB, 1996; PALMER, 2009). O vasto medial hiperplásico é incapaz de contrabalancear a tração exercida pelo vasto lateral, podendo assim, ocasionar o deslocamento lateral da patela (OLMSTEAD, 1996).

A sintomatologia da luxação patelar é variável conforme o grau de luxação, classificando-se em 4 graus, associados à severidade da lesão, que podem evoluir de claudicação intermitente à impotência funcional do membro, causada devido à evolução das alterações ósseas degenerativas (Tabela 1). (PIERMATTEI, 1999).

Tabela 1. Características dos graus de luxação patelar.

\begin{tabular}{cc}
\hline Grau 1 & $\begin{array}{c}\text { Ocorre luxação medial da patela por manipulação, devido à extensão } \\
\text { completa da articulação do joelho. Não há crepitação ou deformidade } \\
\text { óssea. Sinais clínicos brandos ou ausentes. }\end{array}$ \\
\hline Grau 2 & $\begin{array}{c}\text { Ocorre luxação espontânea, a patela retorna naturalmente ao sulco. } \\
\text { Formam-se leves deformidades devido à rotação interna da tíbia e adução } \\
\text { do tarso. Observa-se claudicação intermitente. }\end{array}$ \\
\hline Grau 3 & $\begin{array}{c}\text { A patela encontra-se permanentemente luxada, mas pode ser reduzida } \\
\text { manualmente. Pode ocorrer rotação interna da tíbia e curva em forma de S } \\
\text { da porção distal do fêmur e proximal da tíbia. Há presença de } \\
\text { deformidades ósseas mais graves e significativas. O animal apresenta } \\
\text { andar “agachado" e membros semi-flexionados com rotação interna. } \\
\text { Normalmente o distúrbio é bilateral. }\end{array}$ \\
\hline Grau 4 & $\begin{array}{c}\text { A patela fica permanentemente luxada e de forma irredutível. A tíbia sofre } \\
\text { rotação de } 60^{\circ} \text { a } 90^{\circ} \text { com relação ao seu eixo sagital. Formação de } \\
\text { deformidades ósseas e ligamentares graves. Evolução para impotência } \\
\text { funcional do membro. }\end{array}$ \\
\hline
\end{tabular}

Fonte: SINGLETON (1969)

O tratamento de suporte preconizado para estes casos contempla repouso, administração de analgésicos e fisioterapia, apesar do tratamento cirúrgico ser mais comumente realizado, visto que na maioria das vezes os sinais clínicos manifestados pelos animais são mais evidentes somente em uma fase tardia da doença. Nos casos dos felinos isso é ainda mais considerável, pois a maioria dos gatos afetados raramente apresenta sinais clínicos de claudicação (KLEINE; BERNSTEIN, 2008).

Este trabalho tem como objetivo relatar a ocorrência de luxação lateral congênita patelar em um felino. 


\section{MATERIAIS E MÉTODOS}

Foi atendido no Hospital Veterinário (HOVET) do Centro Regional Universitário de Espírito Santo do Pinhal (UNIPINHAL), um felino macho da raça Pêlo Curto Brasileiro (PCB), com sete meses de idade, apresentando histórico de claudicação e impossibilidade de apoio adequado com o membro posterior direito, adotando uma postura flexionada, impossibilitando uma deambulação normal.

Durante a anamnese, o proprietário relatou que este problema existia desde o nascimento do animal, pois ele nunca havia conseguido estender o membro acometido.

No exame físico avaliou os membros posteriores do animal notando que existia uma impossibilidade de extensão do membro com severa atrofia do músculo vasto lateral, as patelas encontravam-se luxadas lateralmente e incapacitadas de serem reduzidas manualmente.

O animal foi então encaminhado ao setor de Diagnósticos por Imagem do HOVET, para realização de exames radiográficos, com o intuito de confirmar e observar as alterações anatômicas presentes.

Observando a radiografia na projeção ventro-dorsal, notou-se que o animal apresentava luxação lateral da patela direita (Figura 1), na projeção crânio-caudal da articulação fêmuro-tíbio-patelar direita evidenciou-se a presença de hipoplasia do sulco troclear através da técnica de Skyline (Figura 2), caracterizando uma luxação patelar de grau quatro.

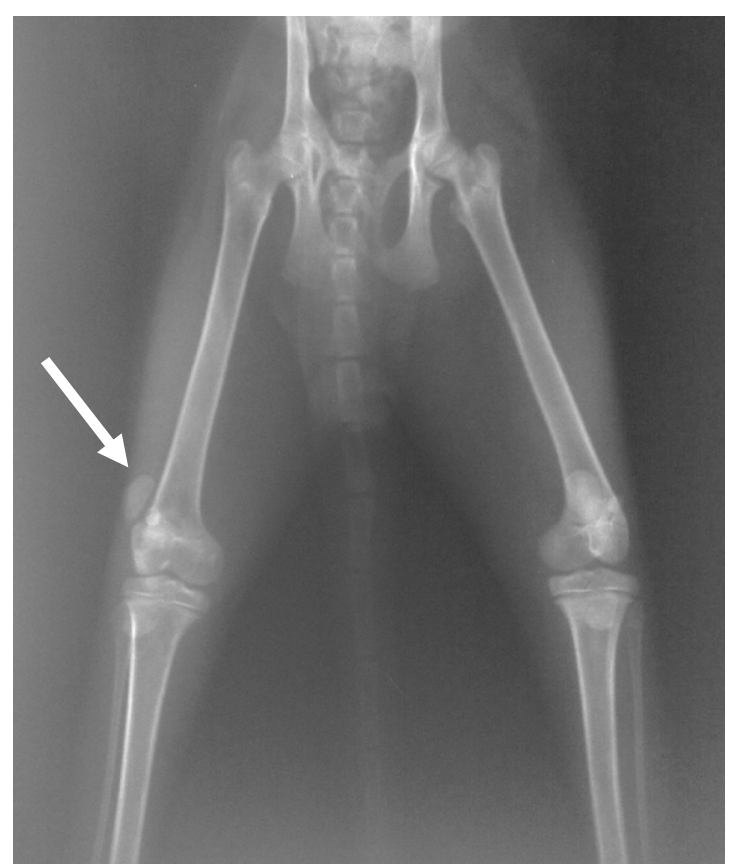

Figura 1: Imagem radiográfica ventro-dorsal da região pélvica, visualização da luxação lateral da patela direita (seta). 


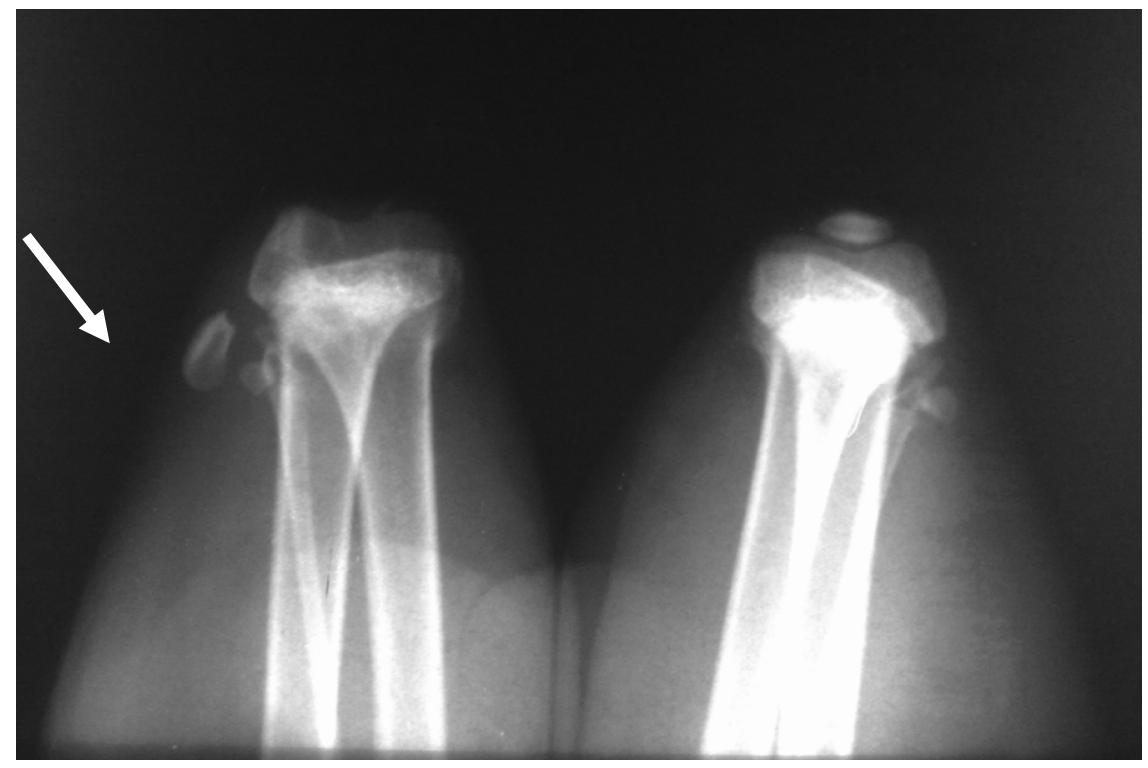

Figura 2: Imagem radiográfica crânio-caudal da articulação fêmuro-tíbio-patelar direita, técnica de Skyline. Visualização de hipoplasia do sulco troclear e patela deslocada lateralmente (seta).

\section{RESULTADOS E DISCUSSÃO}

Após exame das radiografias e analisado o histórico clínico do paciente, o diagnóstico definitivo foi luxação lateral congênita da patela. $O$ animal foi encaminhado para cirurgia onde se realizou a técnica cirúrgica de trocleopastia por desgaste associada à imbricação retinacular lateral da patela.

Segundo Hulse e Johnson (2003), o tratamento cirúrgico desta afecção consiste no reposicionamento da patela em sua posição original, prevenindo sua possível luxação e evitando seu deslocamento do sulco troclear.

As técnicas cirúrgicas utilizadas em pacientes com luxação lateral da patela podem ser a união de técnicas de tecido mole e tecido ósseo, geralmente realiza-se a liberação das restrições laterais impostas pelas fibras musculares neutralizando as forças que atuam sobre a patela, associando-se a este procedimento a trocleoplastia e a transposição da tuberosidade tibial (HULSE; JOHNSON, 2003; PIERMATTEI, 1999).

\section{CONCLUSÃO}

Considerando-se o raro acometimento dos felinos por esta afecção e sua escassa descrição na literatura envolvendo os mesmos, este trabalho serve como referência para o conhecimento geral das características da luxação patelar, acrescentando dados à literatura, 
visando à importância do diagnóstico precoce nos animais, principalmente nos felinos que raramente apresentam sinais clínicos, ressaltando-se que a detecção precoce e a correção imediata são os melhores meios de se evitar as disfunções e agravamentos das claudicações ocasionadas por esta enfermidade.

\section{REFERÊNCIAS}

BOJRAB, M. J. Mecanismos da moléstia na cirurgia dos pequenos animais. 2.ed. São Paulo: Manole, 1996. 1472p.

HULSE, D. A; JOHNSON, A. L. Luxação patelar lateral. Cirurgia de pequenos animais. 2 ed. São Paulo: Roca, 2003.1086p.

KLEINE, K.; BERNSTEIN, M. Luxação medial e lateral da patela. Disponível em:< http://sites.google.com/site/saudecanina/artigos-uteis-aos-leigos-e-aos-veterinarios/luxacaomedial-e-lateral-da-patela-deslocamento-de-rotula>. Acesso em 27 jun. 2011.

OLMSTEAD, M. L. Luxação lateral da patela. Mecanismos da moléstia na cirurgia dos pequenos animais. Manole, São Paulo, SP, 1996, 1472p.

PALMER, R. H. North American Veterinary Conference (NAVC) 2009. Orlando Flórida, 2009.

PIERMATTEI, D. L.; FLO, G. L. A articulação fêmuro-tíbio-patelar. Ortopedia e tratamento das fraturas dos pequenos animais. 3 ed. São Paulo: Manole,1999. 480p.

SINGLETON, W. B. The surgical correction of stifle deformities in the dog. Journal of Small Animal Practice. v.10, n.2, p. 59-69, fev. 1969. 
